\title{
strawberry notch encodes a conserved nuclear protein that functions downstream of Notch and regulates gene expression along the developing wing margin of Drosophila
}

\author{
Arindam Majumdar, ${ }^{1}$ Raghavendra Nagaraj, ${ }^{1}$ and Utpal Banerjee ${ }^{2}$ \\ Department of Molecular, Cell and Developmental Biology and Molecular Biology Institute, University of California, \\ Los Angeles, California 90095 USA
}

\begin{abstract}
The dorsal/ventral (D/V) boundary functions as an organizer in the growth and patterning of the Drosophila wing disc and gives rise to the wing margin in the adult fly. Here we show that strawberry notch (sno) is a downstream component of the Notch signaling pathway and is important for the specification of this organizer. sno encodes a novel nuclear protein conserved in C. elegans, mouse, and humans. Mutations in wing margin genes interact dominantly with sno and loss of sno function results in loss of expression of wingless, vestigial, cut, and $E(\mathrm{spl})-\mathrm{m} 8$ at the $\mathrm{D} / \mathrm{V}$ boundary. In regulating these genes, sno functions in close cooperation with Suppressor of Hairless and Hairless. Finally, sno has no role in lateral inhibition suggesting that it may contribute to the specificity between lateral and inductive Notch signaling pathways.
\end{abstract}

[Key Words: sno; Notch pathway; wing margin; Drosophila development]

Received January 24, 1997; revised version accepted March 25, 1997.

The Notch $(N)$ signaling pathway has been implicated in cell communication events necessary for proper cell fate decisions in many different developmental systems (Artavanis-Tsakonas et al. 1995). The genetic requirement of Notch signaling in developmental decisions was first described in the Drosophila embryo where the central nervous system arises as the selective choice of a bipotential group of cells to become neuroblasts /Lehmann et al. 1983). In mutants in which the Notch signal is compromised, the process of lateral inhibition, essential for making the proper developmental choice, does not occur, resulting in abnormalities in cell fate specification and an overcommitment to neural cell type at the expense of epidermal cells. Similar hypertrophy phenotypes are also seen in Notch mutants during mesoderm and endoderm development and during oogenesis, demonstrating that Notch function in lateral inhibition is not unique to neurogenesis (Corbin et al. 1991; Ruohola et al. 1991; Hartenstein et al. 1992; Xu et al. 1992). Recent studies have suggested an additional role of Notch in cell fate specification that involves an inductive rather than a lateral inhibitory mechanism. The best

\footnotetext{
${ }^{1}$ These authors contributed equally to this work.

${ }^{2}$ Corresponding author.

E-MAIL baneriee@ewald.mbi.ucla.edu; FAX (310) 206-9062.
}

studied example of this type of signaling is in the developing wing disc of Drosophila, where the proper expression of genes responsible for the development of the margin requires the activation of the Notch signal (Couso et al. 1995; Diaz-Benjumea and Cohen 1995; Kim et al. 1995; Doherty et al. 1996).

A number of genes have been identified as members of the Notch signaling pathway based on their mutant phenotype and their genetic and molecular interaction with the Notch receptor, and have been collectively referred to as the Notch group of genes (Artavanis-Tsakonas et al. 1995). These include Serrate (Ser) and Delta (DI), which encode ligands for Notch (Kopczynski et al. 1988; Fleming et al. 1990; Thomas et al. 1991\}, Suppressor of Hairless [Su $(H)]$, Hairless $(H)$, mastermind (mam), and neuralized (neu), which encode nuclear components of the Notch signaling pathway (Smoller et al. 1990; Boulianne et al. 1991; Bang and Posakony 1992; Schweisguth and Posakony 1992), and deltex $(d x)$, which encodes a cytoplasmic protein (Busseau et al. 1994). The exact events following activation of Notch are not yet fully understood; however, studies in Drosophila cell lines suggest that $\mathrm{Su}(\mathrm{H})$ is sequestered in the cytoplasm by binding to the intracellular ankyrin repeats of Notch, and migrates into the nucleus only on the activation of Notch by its ligand Delta (Fortini and Artavanis-Tsakonas 1994). In 
this model, upon Notch signaling, Dx may function to displace $\mathrm{Su}(\mathrm{H})$, which then migrates to the nucleus (Diederich et al. 1994; Matsuno et al. 1995). In the nucleus, $\mathrm{Su}(\mathrm{H})$ is known to positively regulate transcription of the Enhancer of split complex [E(spl)-C] (Jennings et al. 1994; Heitzler et al. 1996), which encodes a series of basic helix-loop-helix (bHLH) type of transcription factors that negatively regulate the pro-neural achaetescute complex (AS-C) genes, therefore promoting epidermal cell fate (Jennings et al. 1994; Kramatschek and Campos-Ortega 1994; Oellers et al. 1994; Singson et al. 1994; Nakao and Campos-Ortega 1996). The AS-C and $E$ (spl)-C genes appear to participate in a dynamic feedback regulatory loop that responds to input from Notch (Campos-Ortega 1993; Wilkinson et al. 1994; Chitnis et al. 1995; Heitzler et al, 1996). This feedback regulation constitutes a critical component of lateral signaling events mediated by Notch.

The Notch pathway also has a crucial role in the development of the Drosophila wing. Recent experimental results implicate both Serrate and Delta as ligands for Notch in the establishment of the Dorsal-ventral (D/V) boundary in the developing wing imaginal disc. The localized activation of Notch at the developing wing margin leads to the $\mathrm{D} / \mathrm{V}$ boundary-specific expression of wingless $(w g)$, vestigial $(\mathrm{vg})$, cut $(\mathrm{ct})$ and members of the E(spl) complex (Diaz-Benjumea and Cohen 1995; Kim et al. 1995; de Celis et al. 1996; Doherty et al. 1996). These genes have a crucial role in regulating growth and pattern formation along the boundary. For example, $v g$ is a master regulator of genes responsible for the assumption of wing identity and loss of $\mathrm{vg}$ function results in complete loss of wing development (Williams et al. 1991, Kim et al. 1996). Similarly, Wg is required along the D/V boundary for the growth and patterning of the presumptive wing margin (Phillips and Whittle 1993; Diaz-Benjumea and Cohen 1995). Mutations in $c t$ and $E(s p l)$ also result in a loss of wing margin formation (Jack and DeLotto 1992; de Celis et al. 1996), but the exact function of these two genes in this system is not completely clear. In genetic assays, $\mathrm{wg}, \mathrm{vg}$, and $c t$ interact with members of the Notch pathway, further confirming that the patterning of the margin involves the regulation of these genes through the activation of Notch (Rabinow and Birchler 1990; Jack and DeLotto 1992; Hing et al. 1994; Couso and Martinez-Arias 1994).

Genetic and phenotypic analyses have shown that mutations in strawberry notch (sno) share common phenotypes with Notch in the developing leg, eye, ovary, and wing of the fly (Coyle-Thompson and Banerjee 1993). sno is essential for embryonic and pupal viability, but adult phenotypes can be examined using temperature sensitive alleles. Mutations in sno both enhance loss-of-function Notch phenotypes, and suppress gain-of-function Notch mutants, in a tissue-specific manner. Moreover, mutations in Notch group genes, such as Ser, $d x$, and $E(s p 1)$, dominantly enhance sno phenotypes. Together, these data imply that the level of Notch signaling is compromised in sno mutants and that sno is a positive regulatory component of the Notch signaling pathway.

\section{Results}

\section{Positional cloning}

Recombination mapping placed the sno locus between furrowed $\left(f_{w}\right)$ and wavy $(w y)$ in the $11 \mathrm{D} / \mathrm{E}$ region of the $X$ chromosome (Lefevre and Peterson 1972). Using deficiencies for the region (Fig. 1A), sno was mapped between the breakpoints of $\mathrm{Df}(1) w y^{54 c}$ and $\mathrm{Df}(1) \mathrm{GP} 1$. A genomic walk bridging the $w y^{54 c}$ and GP1 breakpoints was completed, starting with a pre-existing walk in the region (Wehrli et al. 1993). Recombination mapping with respect to polymorphic markers showed that at least part of the sno gene lay within a $60-\mathrm{kb}$ interval in the middle of the walk (Fig. 1A). Additionally, genetic screens to obtain more alleles of sno yielded a new allele, sno ${ }^{93 i}$, which showed a deletion of $-2 \mathrm{~kb}$ mapping to the clone $\lambda 85$. Fragments from this genomic clone were used to screen a 4- to 8-hr embryonic cDNA library (Brown and Kafatos 1988), and a 5.7-kb cDNA clone, la, which mapped to the genomic region deleted in $s n o^{93 i}$, was isolated. Transformation of sno mutant flies using an hsp70-1a construct or a cosmid including this genomic region rescued all sno phenotypes, including lethality.

The 5.7-kb sno cDNA contains 319 nucleotides of $5^{\prime}$ and 780 nucleotides of $3^{\prime}$ untranslated regions and a single long open reading frame (ORF) whose conceptual translation results in a 1547 -amino-acid protein (Fig. 1B). The Sno amino-acid sequence shows no significant similarites to genes characterized previously. However, two putative nuclear localization signals and two acidic regions are found, suggesting a possible role for Sno in transcriptional activation (Ptashne and Gann 1993).

The Sno protein sequence shows a high degree of similarity to a translated product derived from a Caenorhabditis elegans cosmid sequence (Fig. 1C). The best overlap is in two blocks with residues 318-721 and 997-1205 of the Drosophila sequence. These two regions show $66 \%$ and $71 \%$ identity, respectively, to the C. elegans sequence. Mapping between the two blocks of similarity in the $C$. elegans sequence, is a highly acidic region, corresponding to the second acidic region in the Drosophila sequence. This further suggests that the acidic residues are important for Sno function.

A portion of the Drosophila Sno protein is also conserved in two independent incomplete human cDNAs derived from fetal cochlear epithelial and retinal cDNA libraries. The Drosophila and human proteins were found to be $75 \%$ identical and $88 \%$ similar over 300 amino acids (Fig. 1C). Also, an incomplete cDNA from a mouse embryonic library shows high levels of identity to a portion of Drosophila Sno $63 \%$ identity and $73 \%$ similarity, Fig. 1C). Although no other information is yet available on the genes that are similar to Sno in C. elegans, mouse, and humans, the similarities are striking and suggest a conservation of function for this gene across species.

\section{Sno is a nuclear protein}

Immunohistochemical staining with an antibody de- 

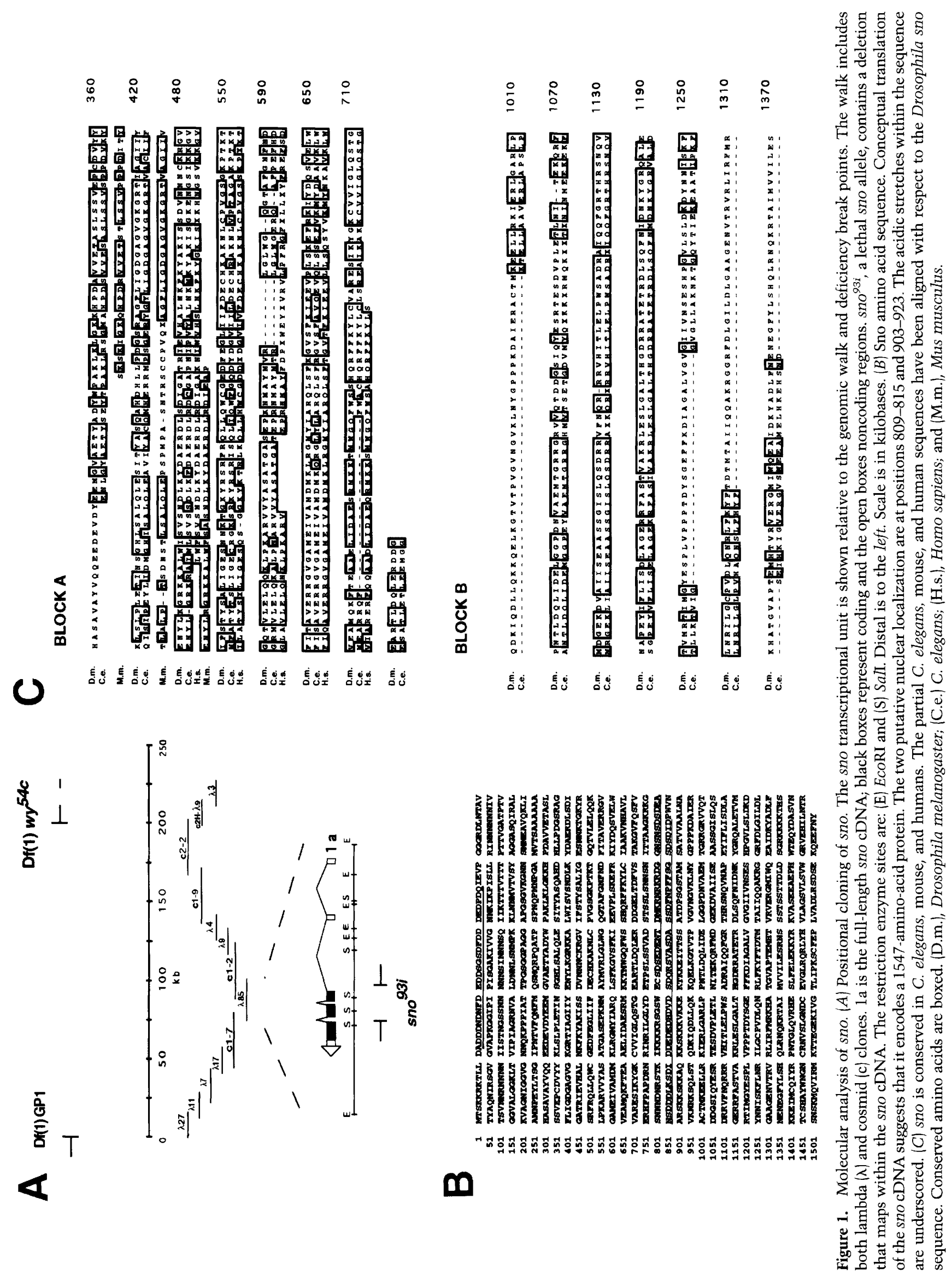
rived against an amino-terminal peptide of Sno showed that it is expressed in the nuclei of many different tissues. This is seen most easily in Malpighian tubules that contain large nuclei (Fig. 2A). Salivary glands show no detectable expression of Sno (Fig. 2B), but when Sno is ectopically expressed using an $h s p 70-s n o$ cDNA construct, its subcellular localization is found to be nuclear
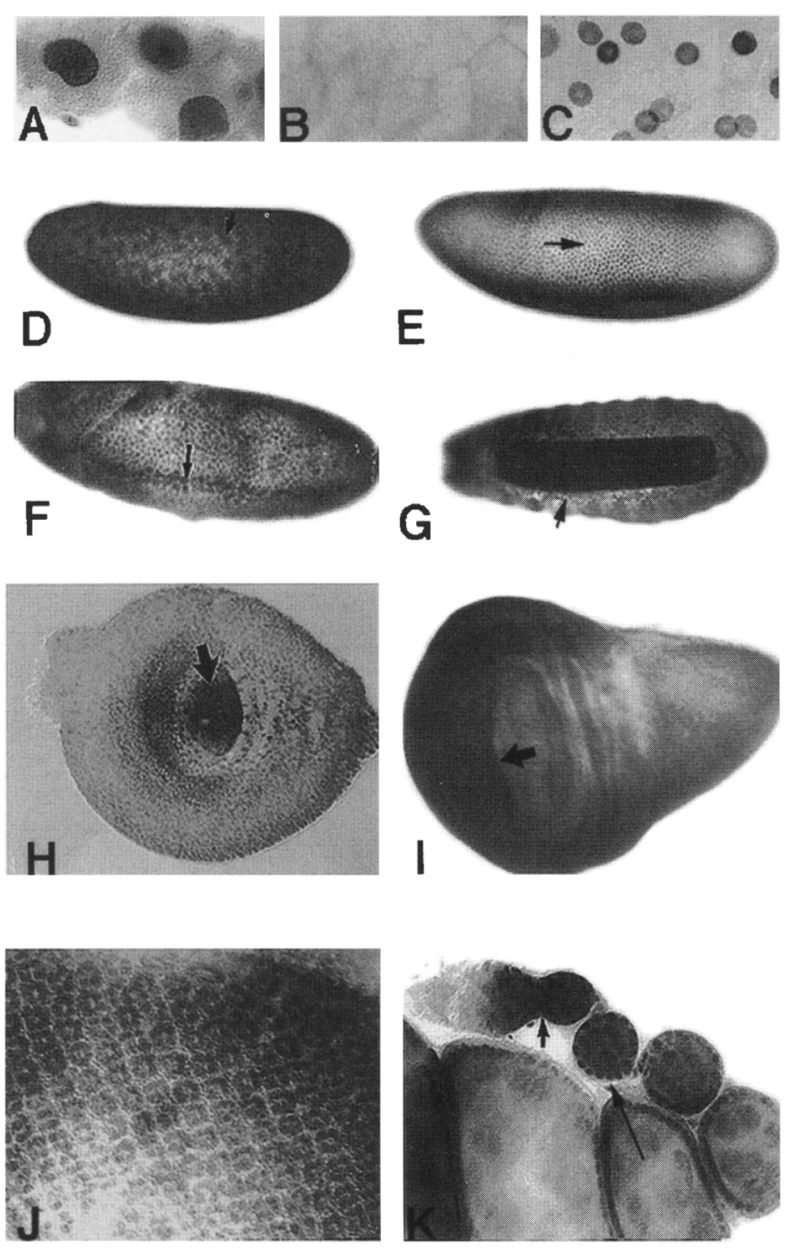

Figure 2. Subcellular localization and expression pattern of the Sno protein. (A) Malpighian tubules stained with Sno antibody show intense nuclear staining. $(B)$ Wild-type salivary glands show no expression of the Sno protein. $(C)$ Upon application of heat shock to larvae carrying a single copy of the $h s p-70-s n o$ cDNA transgene, strong ectopic expression of Sno is seen in salivary gland cell nuclei. (D) Syncytial blastoderm (stage 2). Sno expression is associated with nuclei (arrow). (E) Cellular blastoderm (stage 5). Sno is expressed in all the nuclei (arrow) of the blastoderm. (F) Gastrulation (stage 8). Sno is expressed in all of the nuclei with higher levels of expression seen in the ventral midline cells (arrow). (G) At stage 16, high levels of Sno expression are restricted to the central nervous system (arrow). (H) Sno expression is ubiquitous in third-instar leg discs, with higher levels of expression in the presumptive tarsal segments (arrow). (I) In the third-instar wing disc, Sno is seen in all cells. The arrow marks the $\mathrm{D} / \mathrm{V}$ boundary. (J) In the third-instar eye disc, Sno expression is ubiquitous. $(K)$ In the adult ovary, Sno expression is restricted to the follicle cells (arrows).
(Fig. 2C). Sno was not detected in mesodermal and endodermal tissues; therefore the expression of Sno is not as widespread as Notch, which is found in all three germ layers in the embryo (Fehon et al. 1991).

In the embryo, Sno is first detected in nuclei at the syncytial blastoderm stage (Fig. 2D). This expression is evident before the onset of zygotic transcription. Because no Sno protein is detected in oocytes, this early expression represents the translation of maternally derived sno mRNA. In the cellular blastoderm (stage 5), all nuclei of the embryo, except for the pole cells, appear to contain Sno (Fig. 2E). At gastrulation, Sno is seen transiently in the mesodermal precursors but shuts off as soon as these cells invaginate inside the embryo (data not shown). At stage 8 , when the formation of the midline precursor cells depends on Notch signaling (Menne and Klambt 1994), we observe higher levels of Sno in the midline precursor cells than in the surrounding epidermal cells (Fig. 2F). Between stages 11 and 14, Sno is seen uniformly throughout the epidermis, and finally at around stage 16, high level of expression is restricted to the central nervous system (Fig. 2G).

Sno is expressed in all of the larval imaginal discs. In the leg disc, Sno expression is ubiquitous, although the central tarsal region shows higher levels of expression as compared with that seen in surrounding cells (Fig. $2 \mathrm{H}$ ). All cells in wing (Fig. 2I) and eye (Figure 2J) discs also show high levels of Sno. During oogenesis, Sno protein is detected in follicle cell nuclei, but not in nurse cell or oocyte nuclei (Fig. 2K). The expression of Sno during oogenesis, embryonic and larval development in the wing, leg, eye, and ovary are all consistent with the sno phenotypes revealed by the temperature-sensitive alleles (Coyle-Thompson and Banerjee 1993).

\section{sno function is needed for the expression of wing margin genes}

Because sno seems to function as a member of the Notch group of genes, we asked whether sno is required for the expression of the wing margin genes, wg, $v g, c t$, and $E$ (spl)-m 8 along the $\mathrm{D} / \mathrm{V}$ boundary using reporter lines to assay their expression. Temperature sensitive $s n o^{71 E 3}$ mutants were pulsed at $30^{\circ} \mathrm{C}$ for $36 \mathrm{hr}$ during the wandering third-instar-larval stage and the expression of the various genes along the $\mathrm{D} / \mathrm{V}$ boundary was monitored. The wg enhancer trap line P2041, in which the expression of the $\beta$-galactosidase gene is under the control of the endogenous $w g$ enhancer, was used to assay wg expression (Fig. 3A,C). When $s n 0^{71 E 3}$ larvae were pulsed at the nonpermissive temperature, a dramatic reduction of $w g-l a c Z$ expression, compared with that seen in wild type, was observed along the presumptive margin (Fig. 3B,D). This observed loss of $w g$ expression was specific to the wing margin, as expression of $w g$ in other regions of the wing disc as well as in other imaginal discs was unaffected by the loss of sno function. The expression of $v g, c t$, and $E(s p l)-\mathrm{m} 8$ was monitored using flies bearing the corresponding $\mathrm{D} / \mathrm{V}$ boundary enhancer fused to the lacZ gene (Jack et al. 1991; Williams et al. 1994; Leu- 

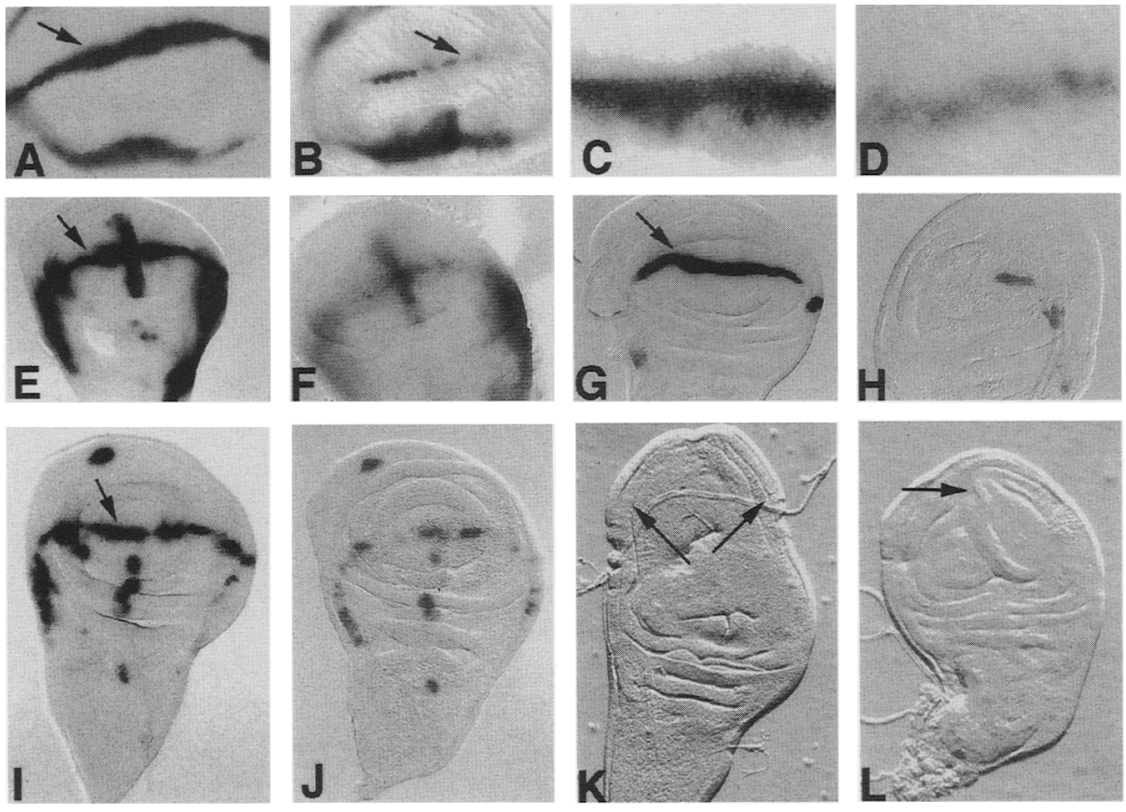

Figure 3. Expression of wing margin genes at the $\mathrm{D} / \mathrm{V}$ boundary is dependent on sno. (A) Wildtype expression of wg monitored using the enhancer trap line p2041. $\mathrm{Wg}$ is expressed along the wing margin (arrow) and in the notum. $(B)$ wg expression in $s n o^{71 E 3}$ heat-pulsed larvae. The expression of $w g-l a c Z$ in the margin is reduced dramatically (arrow) but the expression in the notum is unaffected. $(C)$ Wildtype expression of $w g-l a c Z$ at the margin shown at higher magnification. (D) wglacZ expression at the wing margin in heat-pulsed $s{ }^{71 E 3}$ larvae (higher magnification) showing that cells at the margin are not missing, rather $\mathrm{Wg}$ expression in them is reduced severely. (E) Wild-type expression of a $v g-D / V$ enhancer-lacZ line. Expression is observed along the $D / V$ boundary (arrow) and also along the $\mathrm{A} / \mathrm{P}$ boundary in the wing pouch. $(F)$ Expression of $v g-\mathrm{D} / \mathrm{V}$ enhancer-lacZ reporter in heat-pulsed $s n o^{71 E 3}$ background. The expression along the $\mathrm{D} / \mathrm{V}$ boundary is reduced severely. (G) Wild-type expression of a lacZ reporter fused to the wing margin enhancer of $c t$. Expression is observed along the D/V boundary (arrow). (H) Expression of $c t$ reporter line in heat-pulsed $s n O^{71 E 3}$ background. Expression along the $\mathrm{D} / \mathrm{V}$ boundary is completely eliminated. (I) Wild-type expression of $E$ (spl) $\mathrm{m} 8-1 a c Z$. Expression is observed along the $\mathrm{D} / \mathrm{V}$ boundary (arrow) and in proneural clusters. (J) E(spl) $\mathrm{m} 8-l a c Z$ expression in a heat-pulsed $s{ }^{71 E 3}$ background. Expression along the $\mathrm{D} / \mathrm{V}$ boundary is lost whereas expression in proneural clusters is unaffected. (K) Wing disc from ptc-Gal4; UAS-Ser larva. Ectopic outgrowth of the wing disc in the ventral compartment (arrows) is attributable to the ectopic expression of Ser along the A/P boundary. $(L)$ Wing disc from sno ${ }^{71 E 1} / Y$; ptc-Gal4; UAS-Ser larva. Note the suppression of ectopic growth (arrow).

courtois and Schweisguth 1995). These constructs all respond to the $\mathrm{D} / \mathrm{V}$ signal in the wing disc, showing margin-specific $\beta$-galactosidase expression (Fig. 3E,G,I). When $s n o^{71 E 3}$ larvae containing these reporter constructs were pulsed at the nonpermissive temperature, a loss in reporter expression for $v g, c t$, and $E(s p l)-\mathrm{m} 8$ along the $\mathrm{D} / \mathrm{V}$ boundary was observed, whereas the expression of these reporters in other regions of the wing disc was unaffected (Fig. 3F,H,J). In some instances $\beta$-galactosidase expression is reduced dramatically, but not completely eliminated, perhaps attributable to the fact that when functioning independently of the rest of the gene these enhancers give unusually strong expression, and because the $\beta$-galactosidase product is very stable. Unlike the wing margin genes, the expression of Sno itself is ubiquitous throughout the wing disc (Fig. 2I) and is not dependent on Notch function (data not shown).

To establish that the effects of Sno are not upstream of Notch, we made use of the Gal4-UAS system to activate the Notch pathway ectopically along the anterior/posterior (A/P) boundary using a ptc-Gal4/UAS-Ser combination (Brand and Perrimon 1993; Speicher et al. 1994). This results in misexpression of Ser along the $A / P$ boundary and causes an ectopic outgrowth of the wing pouch in the ventral compartment (Fig. 3K; Speicher et al. 1994). We reasoned that if Sno functions upstream of Notch, then inactivation of sno using a temperature-sensitive allele should have no effect on this ectopic out- growth. In fact, when $s n o^{71 E 1}$, a strong hypomorphic temperature-sensitive allele, was introduced into the Ptc-Gal4/UAS-Ser background and pulsed for $12 \mathrm{hr}$ at $30^{\circ} \mathrm{C}$, the ectopic outgrowth in the ventral compartment was suppressed entirely (Fig. 3L). In this experimental protocol, Ser expression is under the control of a heterologous promoter; therefore, the suppression of ectopic wing growth on loss of Sno indicates that Sno functions downstream of Ser. Because Ser has been shown to bind directly to Notch at the cell membrane, and Sno is a nuclear protein, this result also suggests that Sno functions downstream of Notch. This conclusion is consistent with our earlier genetic data that had suggested that sno functions downstream of Notch (Coyle-Thompson and Banerjee 1993).

\section{Mutations in wing margin genes dominantly interact with sno}

The function of Sno in regulating the expression of several fate determining genes along the wing margin suggested that mutations in these genes should interact prominently with sno. Flies bearing the temperaturesensitive allele $s n o^{71 E 3}$ show a modest loss of wing margin tissue when raised at $23^{\circ} \mathrm{C}$ (Fig. 4E). When such flies were also made heterozygous for a single copy loss of $w g$, extensive loss of wing margin tissue was observed suggesting a dominant synergistic interaction between $w g$ 
Figure 4. Genetic interactions between sno and mutations in wing margin genes. Adult wings from flies of various genotypes are shown. (A) Wild type. $(B) w g^{t s} /+$. These wings are identical to wild type. $(C) \mathrm{vg}^{1} /+$. These wings are wild type. $(D) c t^{53 d} / Y$. Note the slight notching of the wing margin. (E) $s n o^{71 E 3} / Y$ at $23^{\circ} \mathrm{C}$. At this temperature a slight notching of the wing margin is seen. $(F) s n o^{71 E 3} / Y ; w^{t s} /+$ at $23^{\circ} \mathrm{C}$. The wing margin phenotype of $s n o^{71 E 3}$ is dominantly enhanced by a single copy loss of $w g$. (G) $s n o^{71 E 3} / Y ; v^{1} /+$ at $23^{\circ} \mathrm{C}$. Dominant enhancement of wing margin defects of $s n o^{71 E 3}$ is caused by a single copy loss of $\mathrm{vg}$. (H) $\mathrm{sno}^{71 E 3} \mathrm{Ct}^{53 d} / \mathrm{Y}$ at $23^{\circ} \mathrm{C}$. Note the synergistic interaction between $s n o^{71 E 3}$ and $c t^{53 d}$ wing margin phenotypes.
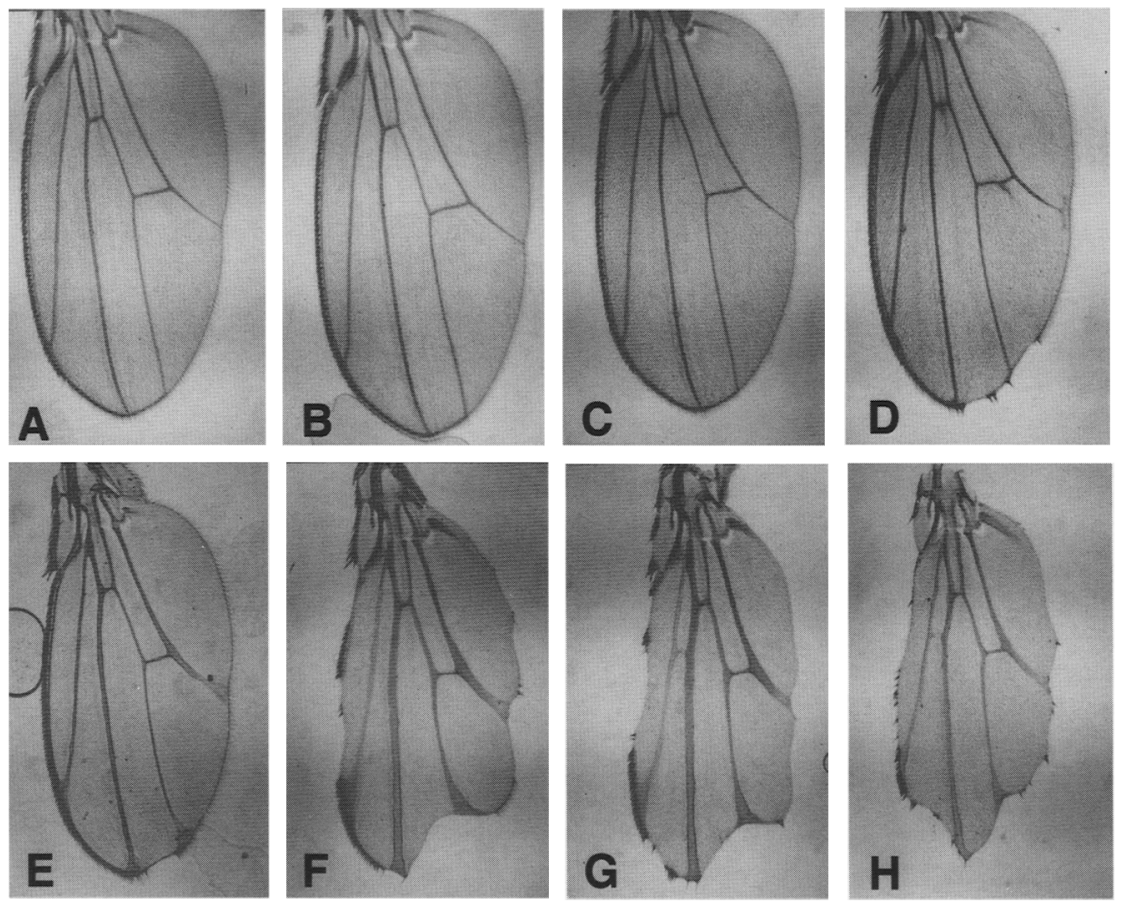

and sno (Fig. 4F). In similar experiments, $s n o^{71 E 3}$ flies with a single copy loss of $\mathrm{vg}$ also resulted in a dominant enhancement of wing margin defects and exhibited extensive loss of wing margin tissue (Fig. 4G). Finally, a genetic combination of $c t^{53 d}$, a weak allele of $c t$, with sno ${ }^{71 E 3}$ shows extensive loss of wing margin tissue, suggesting a synergistic interaction between sno and ct (Fig. $4 \mathrm{H}$ ). These results are reminiscent of the interaction of Notch with wg, vg, and ct (Rabinow and Birchler 1990; Jack and DeLotto 1992; Couso and Martinez-Arias 1994; Hing et al. 1994) and further establish that sno, like Notch, has a crucial role in the establishment of $D / V$ boundary fate by participating in a common genetic pathway that regulates wing margin-specific genes. In addition to the wing margin defects, sno mutants also exhibit thickening of wing veins (Coyle-Thompson and Banerjee 1993; Fig 4E). This is likely to be a secondary consequence of defective wing pouch development caused by improper $\mathrm{D} / \mathrm{V}$ boundary specification. This same phenotype can also be seen in some of the other $\mathrm{D} / \mathrm{V}$ boundary genes such as $\mathrm{vg}$ and Ser (Fleming et al. 1990; Williams et al. 1991).

\section{sno genetically interacts with nuclear components of Notch signaling}

Two nuclear proteins identified previously that function downstream of Notch have been shown to regulate margin-specific genes. These are $\mathrm{Su}(\mathrm{H})$ and Hairless. $\mathrm{Su}(\mathrm{H})$ is a sequence specific DNA binding factor that helps transduce the Notch signal from the membrane to the nucleus (Fortini and Artavanis-Tsakonas 1994), whereas Hairless is a nuclear factor that binds $\mathrm{Su}(\mathrm{H})$, preventing it from binding DNA (Brou et al. 1994). Because our results show that Sno is also a nuclear component downstream of Notch, we looked for genetic interactions of sno with $\mathrm{Su}(\mathrm{H})$ and Hairless. A single copy loss of Hairless, achieved using the $H^{E 31}$ allele, is able to suppress sno wing margin defects (Fig. 5C), suggesting that Hairless and sno have closely related antagonistic activities downstream of the Notch pathway. An equally strong but opposite effect was seen with $\mathrm{Su}(\mathrm{H})$. At $23^{\circ} \mathrm{C}$, the double mutant $s n o^{71 E 3} / Y$; $S u(H)^{A r 9} /+$ flies die at pupal stages. At $20^{\circ} \mathrm{C}$, which is a fully permissive temperature for $s_{0} o^{71 E 3}$, the $s n o^{71 E 3} / Y, S u(H)^{A r 9} /+$ double mutant flies do eclose, but show severe defects in the wing margin (Fig. 5F). These results suggest that sno and $S u(H)$ cooperate closely in the patterning of the wing. As Sno contains an apparent activation domain but not any obvious DNA-binding motif, and mammalian $\mathrm{Su}(\mathrm{H})$ is known to bind proteins that are important for transcriptional activation (Heish and Hayward 1995), it was reasonable to test if $\mathrm{Sno}$ and $\mathrm{Su}(\mathrm{H})$ interact directly. In coimmunoprecipitation assays, yeast two-hybrid systems, and in vitro GST-Su(H) fusion protein-binding assays, we were unable to detect any direct interaction between Sno and $\mathrm{Su}(\mathrm{H})$. This may either mean that the two proteins work in parallel or that they interact too weakly for their binding to be detected in our assays.

\section{sno is specific to inductive Notch signaling}

Notch function has been best described in pathways that cause lateral inhibition (Artavanis-Tsakonas and Simpson 1991; Campos-Ortega 1993). Our earlier studies had shown that embryos with null mutations in sno do not 

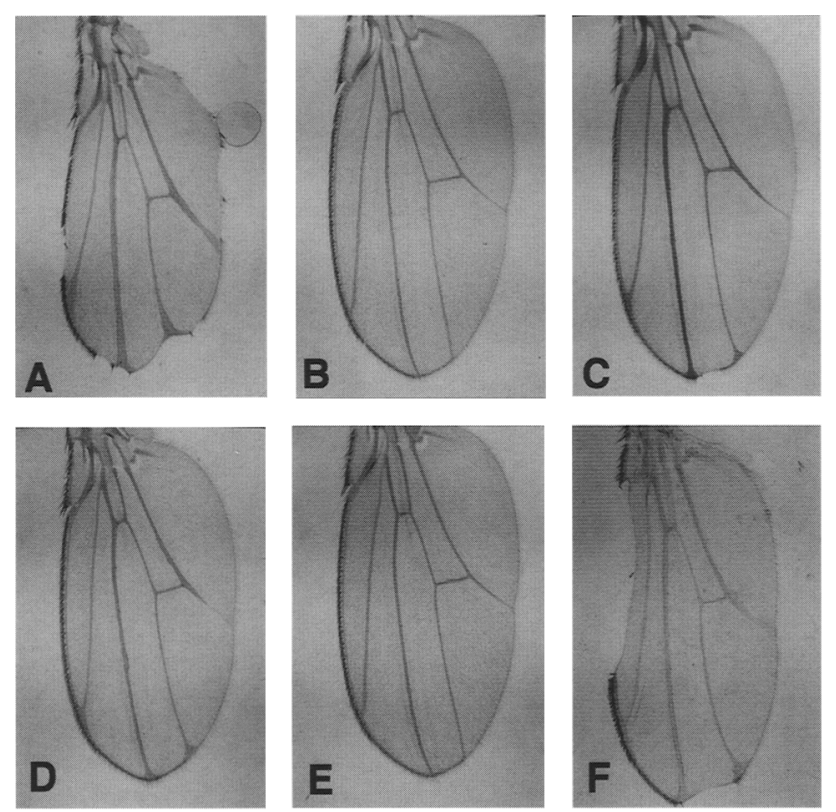

Figure 5. Genetic interactions of sno with $\mathrm{Su}(H)$ and Hairless. Adult wings from flies of various genotypes are shown. $(A)$ $s n o^{71 E 1} / Y$ at $20^{\circ} \mathrm{C}$. This allele is stronger than $s n o^{71 E 3}$ and shows wing margin defects at this temperature. $(B) H^{E 31} /+$. These wings are wild type. $(C) s n o^{71 E 1} / Y ; H^{E 31} /+$ at $20^{\circ} \mathrm{C}$. A complete suppression of the wing margin defects of $s n O^{71 E 1}$ is caused by a single copy loss of Hairless. $(D) s n 0^{71 E 3} / Y$ at $20^{\circ} \mathrm{C}$. At this temperature, these wings are essentially wild type. $(E)$ $\mathrm{Su}(H)^{A r 9} /+$. These wings are wild type. $(F) S n O^{72 E 3} / Y ; \mathrm{Su}(H)^{A r 9} /+$ at $20^{\circ} \mathrm{C}$. Extensive loss of the anterior margin tissue in the wing can be seen.

show neural hypertrophy phenotypes (Coyle-Thompson and Baneriee 1993). Also, temperature shift experiments using $S n \mathrm{O}^{71 E 3}$ showed no hypertrophy of the embryonic nervous system. The interpretation of these results is complicated by the fact that there is considerable maternal contribution of Sno in the embryo and that we were unable to generate germ-line clones with the sno null mutation $s n o^{E F 531}$ (Coyle-Thompson and Baneriee 1993). We therefore investigated the possible role of Sno in lateral signaling in three additional and separate processes.

Each microchaete sensillum on the adult notum arises during pupal development from a sensory organ precursor (SOP) cell (Hartenstein and Posakony 1989). A single SOP is specified from within a group of equipotential cells called the proneural equivalence group through Notch mediated lateral signaling. In the absence of Notch signaling, created by maintaining $N^{t s}$ flies at $37^{\circ} \mathrm{C}$ for $12 \mathrm{hr}$ during $0-2 \mathrm{hr}$ of pupal development, multiple SOPs develop from each field of competent cells, giving rise to a lawn of microchaetes on the pupal notum (Fig. 6B; Hartenstein and Posakony 1990). Under identical conditions, sno flies did not show any overproduction of microchaetes, suggesting that lateral signaling during SOP specification is not affected in this mutant (Fig. 6C). Although this is a negative result, the temperature used to inactivate the sno alleles is clearly nonpermissive for all other sno phenotypes, and in fact, causes lethality at late pupal stages.

In the wing disc, specification of a single SOP within each pro-neural cluster was monitored using the neulacZ enhancer trap line A101, which marks the SOP that gives rise to each sensory bristle organ (Fig. 6D; Huang et al. 1991). The absence of Notch function results in two phenotypes in the wing disc. Along the wing margin, loss of Notch function leads to a loss of Wg expression and a consequent loss of A101 expressing cells in the anterior of the wing (Fig. 6E; Phillips and Whittle 1993; Rulifson and Blair 1995). Elsewhere in the wing, absence of Notch function results in a lack of lateral signaling and produces a neurogenic phenotype, appearing as an expansion of A101 expressing clusters of cells (Fig. 6E; Rulifson and Blair 1995). In $S n o^{71 E 3}$ flies, pulsed at the nonpermissive temperature, loss of A101 expression was observed at the wing margin attributable to the requirement of sno for $\mathrm{Wg}$ expression. However, no neurogenic defect was observed in nonmargin proneural cluster development, suggesting again that lateral signaling is unaffected in sno mutants (Fig. 6F).

In the eye disc, neurogenesis was monitored by staining with monoclonal antibody $22 \mathrm{C} 10$, which highlights developing neurons (Zipursky et al. 1984). During normal third-instar eye imaginal disc development, lateral signaling ensures regular spacing between differentiating photoreceptor clusters behind the morphogenetic furrow (Fig. 6G). Absence of Notch results in a lack of lateral signaling leading to neural hypertrophy behind the morphogenetic furrow (Fig. 6H; Cagan and Ready 1989). When $s o^{71 E 3}$ larvae were heat-pulsed during ommatidial development and stained with $\mathrm{mAb} 22 \mathrm{C10}$, no neural hypertrophy phenotype was observed, further supporting the view that sno does not function in lateral signaling (Fig. 6I). The strongest hypomorphic allele of sno $\left(s n O^{E 1}\right)$ when placed over a deletion and raised at $30^{\circ} \mathrm{C}$ gives a phenotype that is equivalent to null. Using these conditions during wing, eye, and notum development, we obtained the same results as are shown in Figure 6 (data not shown).

Although the mutant conditions used here are sufficient to inactivate sno function in many tissues, one could argue that the threshold levels for lateral signals are lower than that for inductive signals. To rule out this possiblity, we used a null allele of $s n o, s n o^{E F 531}$, to generate somatic clones in the eye. The $s n O^{E F 531} / s n O^{E F 531}$ clone does show one of the phenotypes ascribed previously to sno, that is, the recruitment of a mystery cell as an outer neuron (Fig. 6); Coyle-Thompson and Banerjee 1993). This demonstrates that the clone is homozygous for the mutation. In contrast, the clone does not show hypertrophy of neural development as is seen with loss of Notch function (Cagan and Ready 1989). Taken together, the above results, obtained from three separate tissues, indicate that sno does not function in lateral signaling within pro-neural equivalence groups and demonstrate that Sno participates only in inductive Notch signaling events. 
Figure 6. sno does not participate in lateral signaling of Notch. (A) Notum from a wild-type adult fly showing the regular arrangement of bristles. $(B)$ Notum from heat pulsed $N^{t s}$ fly during pupation showing a hypertrophy phenotype of bristle development. (C) Notum from $s n o^{71 E 3} / Y$ fly heatpulsed during pupation. No hypertrophic bristle phenotype is seen. (D) neu-lacZ enhancer trap line A101 expression in wildtype wing imaginal disc. Expression is observed in the SOP of each of the proneural clusters. (E) A101 expression in wing disc from $N^{t s}$ males pulsed for $36 \mathrm{hr}$. Loss of A101 expression was observed in anterior bristle precursors along the margin attributable to the dependence of $\mathrm{Wg}$ on the Notch signal. Additionally, there is an increase in the number of SOPs within the proneural clusters (arrow) attributable to loss of lateral signaling mediated by Notch. (F) A101 expression in heat pulsed sno ${ }^{71 E 3}$ wing disc. A loss of expression of A101 is seen along the anterior bristle precursors at wing margin. However, proneural clusters outside the wing margin are unaffected. $(G)$ Eye disc from wild-type larvae stained with monoclonal antibody $22 \mathrm{C} 10$. Note the regular organization of photoreceptor clusters behind the morphogenetic furrow (arrow). (H) Eye disc from heat-pulsed $N^{\text {ts }}$ larva stained with the $22 \mathrm{C} 10$ antibody. Neural hypertrophy causing enlarged size of clusters is seen behind the furrow (arrow). (I) Eye disc from heat pulsed $s n o^{71 E 3} / Y$ larva stained with $22 \mathrm{C} 10$ antibody. No neural hypertrophy is evident behind the furrow. (J) Section through a sno ${ }^{E F 531}$ clone in an adult eye. Note the mystery cell conversion phenotype in some mutant ommatidia (arrows). However, no neural hypertrophy is evident despite complete loss of sno function.

\section{Discussion}

The establishment of the $\mathrm{D} / \mathrm{V}$ boundary in the wing imaginal disc results from a series of hierarchical steps (Williams et al. 1993). An early event in this process is the activation of apterous, a LIM domain containing transcription factor in the dorsal compartment of the wing disc (Cohen et al. 1992). Apterous, in turn, regulates the expression of Fringe, a boundary recognition molecule in the dorsal compartment (Irvine and Weischaus 1994). Apposition of Fringe expressing (dorsal) and Fringe nonexpressing (ventral) cells causes a local upregulation of Ser and the activation of Notch at the ventral edge of the boundary (Kim et al. 1995). Similarly, Delta is required for the activation of Notch on the dorsal aspect of the boundary (Doherty et al. 1996). Therefore, activation of Notch occurs as a result of the asymmetric activity of its ligands on either side of the boundary, giving rise to the symmetrical expression of critical wing margin genes along the presumptive wing margin. These margin genes include $w g, v g, c t$, and $E(S p l)-\mathrm{m} 8$ (Couso et al. 1994, 1995; Diaz-Benjumea and Cohen 1995; Doherty et al. 1996). The expression of these genes along the $\mathrm{D} / \mathrm{V}$ boundary is essential for the cells along the margin to function as a classical organizer (Spemann 1938) for the normal outgrowth of the wing imaginal disc. In this report we have shown that sno is a critical component of the Notch pathway that participates in the proper specification of this organizer.

Previous genetic analysis of sno has suggested that this gene is likely to encode a positive component of the Notch signaling pathway (Coyle-Thompson and Banerjee 1993). This conclusion was primarily based on the fact that mutations in genes belonging to the Notch group interact strongly with sno. The genetic and molecular analysis presented here confirms our earlier prediction and suggests that Sno functions downstream of Notch in controlling the expression of genes that respond to the localized signaling processes initiated by Notch. In the wing disc, the primary role of sno is to control the expression of the margin-specific genes $\mathrm{wg}$, $v g, c t$, and $E(s p l)-\mathrm{m} 8$ along the $\mathrm{D} / \mathrm{V}$ boundary. This conclusion is consistent with the genetic analysis showing that mutations in these wing margin genes enhance sno mutant phenotypes. Based on its nuclear localization, Sno would be expected to function in concert with $\mathrm{Su}(\mathrm{H})$, 
and as expected, $\mathrm{Su}(H)$ mutants dominantly enhance sno wing margin phenotypes. Additionally, $S u(H)$ mutants are similar to sno in having a small wing pouch and in lacking Vg expression along the D/V boundary (Couso et al. 1995). It is of particular significance that Kim et al. (1996) have shown that the isolated $750-b p$ D/V boundary enhancer of $v g$ contains a single $\mathrm{Su}(\mathrm{H})$-binding site, which when mutated, eliminates $\mathrm{Vg}$ expression along the $\mathrm{D} / \mathrm{V}$ boundary. In this report we have shown that transcription initiated by that same enhancer element is also dependent on functional Sno protein. Whereas Sno does not contain any known DNA binding motifs, it does contain acidic stretches of amino acids resembling transcriptional activation domains. Therefore, it is possible that Sno binds to a second DNA-binding protein to activate transcription from this enhancer. We have been unable to demonstrate that this second protein is $\mathrm{Su}(\mathrm{H})$, but our results have not completely ruled out this possibility. The expression of the $\mathrm{m} 8$ transcript of $E$ (spl) also depends on functional $\mathrm{Su}(\mathrm{H})$-binding sites within its enhancer (Bailey and Posakony 1995; Leucourtois and Schweisguth 1995). Again, our results show that the same enhancer also requires functional Sno protein for its activation along the $\mathrm{D} / \mathrm{V}$ boundary. In all respects, $\mathrm{Su}(H)$ and sno give rise to similar phenotypes during wing development and the observed synergy between sno and $\mathrm{Su}(\mathrm{H})$ is likely to translate into a close cooperation between them at the molecular level.

\section{Inductive vs. lateral signaling of Notch}

The developmental consequences of Notch function are dependent on the context in which the signaling takes place. For example, in the nervous system, Notch functions in lateral signaling between members of the proneural equivalence group to restrict the expression of neuronal fate to a single cell within the proneural cluster. In contrast, Notch signaling at the wing margin is inductive, in that activation of the signal in a particular cell is important for the assignment of the D/V boundary fate to that cell. Given that the ligand and the receptor molecules are the same for inductive and lateral signaling processes, it seems likely that components downstream of Notch are responsible for insuring the specificity of the signaling process.

The results of this study suggest the possibility that Sno is a downstream component that is specific to Notch inductive signaling events in Drosophila. Most mutants in the Notch signaling pathway, including Notch, Dl, $\mathrm{Su}(H)$, and $E(s p l)$ are associated with a neurogenic or hypertrophy phenotype during nervous system development. sno mutants do not share this phenotype with these genes, and sno therefore seems to be a member of an emerging group of nonneurogenic Notch pathway genes. During eye development in the third-instar larva, and sensillum development in the pupa, sno mutants do not show the neural hypertrophy phenotypes that are seen with Notch. During wing development, lateral signaling and SOP specification seem to be perfectly operational in sno mutants, wheres the inductive events in the neighboring margin are clearly affected. These results support the idea that sno is required in some, but not all, Notch signaling events. The selective activation of Sno in signal receiving cells may confer the specificity for inductive versus lateral signaling. Furthermore, these results imply that lateral and inductive Notch signaling may invoke separate sets of downstream genes and therefore have different genetic requirements. Like Sno, Numb, a negative regulator of Notch signaling, appears to function in a subset of Notch-mediated events. Numb function is needed for the Notch mediated specification of the MP2 lineage (Spana and Doe 1996). However, loss or overexpression of Numb during development does not alter Notch-mediated lateral signaling events (Rhyu et al. 1994; Jan and Jan 1995; Spana et al. 1995). Some genes, like $\operatorname{Su}(H)$, may belong to a common pool of genes required for both types of signaling whereas other genes, like sno, may be specific for a single type of signaling event. A counterexample for Sno in this respect could be Neu, which may function specifically in lateral signaling as Sno does in inductive pathways, because $\mathrm{Neu}$ is not expressed along the $\mathrm{D} / \mathrm{V}$ boundary and does not interact genetically with sno at the wing margin (Coyle-Thompson and Banerjee 1993). Therefore, the Notch pathway may function in different developmental contexts by coopting different downstream components.

In C. elegans, two separate Notch receptor homologs, Lin-12 and Glp-1, function in separate developmental pathways (Austin and Kimble 1987). Glp-1 is involved in inductive signaling in the gonad and in the early embryo, whereas Lin-12 function is largely restricted to lateral signaling during many different stages of development (Greenwald et al. 1983). However, even in the worm, the specificity of the response of the two sets of receptors does not seem to depend on the receptors themselves, because they can be made to function interchangeably in inductive versus lateral signaling pathways (Fitzgerald et al. 1993). Therefore, in C. elegans, as in Drosophila, it is possible that a differential response to common signal transduction pathways might be brought about by downstream molecules similar to Sno.

\section{Evolutionary conservation of Sno}

The similarity of Sno to translated sequences from human, mouse, and C. elegans suggests that Sno is an evolutionarily conserved protein. This is particularly important because most of the other components of the Notch pathway have also been found to be structurally and functionally conserved from worms to mammals (Austin and Kimble 1989; Tax et al. 1994; Lindsell et al. 1995; Christensen et al. 1996). In vertebrates, the Notch signaling pathway has a crucial role in the patterning of the nervous system. For example, functional levels of Delta control neurogenesis in Xenopus (Chitnis et al. 1995), and inductive signaling via Notch is important in the developing spinal cord and hindbrain in chicken (Myat et al. 1996). In humans, truncations of Notchl results in T-cell leukemia (Ellisen et al. 1991) and truncation of Notch3 causes an adult onset neurological abnormality 
(Joutel et al. 1996). Finally, vertebrate limb development shows striking similarities with the development of the wing in flies. The apical ectodermal ridge (AER) is an organizer with similarities to the $\mathrm{D} / \mathrm{V}$ boundary of the wing disc (Riddle et al. 1995). The dorsal ectoderm expresses Wnt7a (Parr and McMohan 1995), a homolog of $w g$, and the Notch ligands Ser and Delta are expressed in flanking cells much the same way as they do along the $\mathrm{D} / \mathrm{V}$ boundary in flies (Myat et al. 1996; Shawber et al. 1996). Therefore, it seems clear that the Notch pathway has an important role in many different developmental decisions across species. One unfailing characteristic of this pathway is the context dependence of its response. It seems possible that this context dependence results from downstream nuclear components such as Sno. It would therefore be interesting to investigate the relationship between Sno homologs identified in this study with Notch during vertebrate development.

\section{Materials and methods}

\section{Molecular cloning}

As an entry point for the genomic walk, we used a $47-\mathrm{kb} \lambda$ clone walk from the region (kind gift of Marcel Wehrli; Wehrli et al. 1993). A new chromosomal walk was initiated from these clones using Tamkun $\lambda$ and cosmid DNA libraries. For the isolation of the sno cDNA, $\sim 250,000$ clones were screened from a 4- to 8-hr embryonic cDNA library (Brown and Kafatos 1988). For transformation rescue, the sno cDNA was excised with HindIII and EcoRI, blunt ended with Klenow, and subcloned into the StuI site of pCasper-hsp70. For further manipulation, the sno cDNA could then be released with EcoRI.

\section{Transformation rescue}

For transformation rescue, $\mathrm{CsCl}$ pure $500 \mathrm{ng} / \mu \mathrm{l}$ pCasper-Hsp70sno la was mixed with $300 \mathrm{ng} / \mu \mathrm{l}$ pUChs $\pi \Delta 2-3$ helper plasmid and injected into $w^{1118}$ embryos using standard protocol (Rubin and Spradling 1982). Parallel transformations were done with cosmid 1-15, which includes the entire sno gene. For hsp70-sno, 1500-1700 embryos were injected and $12 \mathrm{w}^{+}$transgenic lines were recovered. For c1-15, 2200 embryos were injected and 12 transformants were recovered. Transformant males were crossed to sno/FM7c females and the sons were assayed for rescue. All c1-15 transformant lines rescued sno lethal and temperature-sensitive phenotypes. Two $h s p 70-s n o$ transformant lines rescued lethality and temperature-sensitive phenotypes without heat shock. The remainder of the lines rescued with heat shock at $30^{\circ} \mathrm{C}$. hsp 70 -sno flies have no phenotype on their own.

\section{Sequencing and database search}

Sequencing was done using the protocols and reagents of the USB Sequenase kit. The sno cDNA was sequenced on both strands and the sequence was compiled and edited using the Sequencher v2.1 program (Gene Codes Corporation!. The first methionine in the reading frame is the start methionine, because antibodies raised against 15 amino acids immediately following this methionine could detect the endogenous Sno protein. In addition, the adjacent sequence matches the Drosophila consensus for translation starts (Cavener 1987). Database searches were performed with the BLAST Network Service (Altschul et al. 1990).

\section{$\alpha$-Sno antibody}

The 15-mer oligopeptide TSKKRKTLLDADDDN corresponding to the Sno amino terminus was synthesized by the UCLA Peptide Synthesis Facility. The oligopeptide was sent to the Berkeley Antibody Company, where it was injected into rabbits to make antibodies. Bleeds were tested on Western blots. Sno antibody was affinity purified using the 15-mer oligopeptide on Bio-Rad Affi-Gel 10 and frozen at $-70^{\circ} \mathrm{C}$ in PBS. On Western blots, affinity purified Sno antibody was used at a 1:500 dilution that detected a single band with a molecular weight of $140 \mathrm{kD}$, the predicted size of the Sno protein.

\section{Immunocytochemistry}

Imaginal discs were dissected in phosphate buffer and fixed in PLP with $4 \%$ paraformaldehyde for $20 \mathrm{~min}$ at room temperature. Incubation with Sno antibody was carried out overnight at $4^{\circ} \mathrm{C}$ at 1:250 dilution. Secondary antibody (Goat anti-Rabbit) was used at l:1000 and the staining was visualized using DAB with nickel (Coyle-Thompson and Banerjee 1993).

Embryos were fixed in PEMS/heptane/4\% formaledehyde for $10 \mathrm{~min}$. Vitelline membrane was removed using methanol and embryos that were stained with anti-Sno antibody at 1:200 dilution (Ashburner 1989).

\section{Detection of $\beta$-galactosidase activity}

To detect $\beta$-galactosidase activity in imaginal discs, mature third-instar larvae were dissected in PBS, fixed in $4 \%$ glutaraldehyde for $20 \mathrm{~min}$, washed in PBS for $10 \mathrm{~min}$, and stained as described (Ashburner 1989). Discs were mounted in glycerol for microscopic analysis.

\section{Phenotypic studies}

Double mutants of $s n O^{71 E 3}$ with $v^{1}$ (from Bloomington Stock center), $w g^{I L 114}$ (from A. Martinez-Arias, Cambridge University, $\mathrm{UK}$ ), $c t^{53 d}$ (from J. Jack, University of Connecticut, Farmington), $\mathrm{Su}(H)^{A r 9}$, and $H^{E 31}$ (from J. Posakony, University of California, San Diego) were raised at $23^{\circ} \mathrm{C}$.

For the temperature-shift experiments, late second-and early third-instar larvae were collected and heat-pulsed at $30^{\circ} \mathrm{C}$ for 12,24 , or $36 \mathrm{hr}$. Wing discs were then dissected and stained with $\mathrm{X}$-gal to reveal $\beta$-galactosidase reporter gene expression. Effects were observed with shorter shifts, but the strongest effects reported here were seen with the 36-hr shift. P-2041 wg-lacZ was obtained from the Bloomington Stock Center. The $v g-l a c Z$ transformant (gift of S. Carroll, University of Wisconsin, Madison) contains a 750-bp D/V boundary enhancer of the $v g$ gene fused to $\operatorname{lacZ}$ (Williams et al. 1994). The $c t^{H Z-2}$ reporter construct (gift from J. Jack) includes the wing margin enhancer of the $c t$ gene fused to $1 a c Z$ (Jack et al. 1991); $E$ (spl)-m8-lacZ (from $\mathrm{J}$. Campos-Ortegal contains a $2.61-\mathrm{Kb}$ upstream sequence of $E$ (spl)-m8 fused to the $1 a c Z$ gene (Kramatschek and CamposOrtega 1994).

For temperature-shift experiments in the third-instar eye imaginal disc, early third-instar larvae were collected over $1 \mathrm{hr}$ and incubated in a $32^{\circ} \mathrm{C}$ waterbath for $12 \mathrm{hr}$ as in Cagan and Ready (1989). Eye discs were then dissected, fixed, and stained with mAb $22 \mathrm{C} 10$ to visualize neuronal differentiation (Zipursky et al. 1984).

For temperature-shift experiments during bristle develop- 
ment, 0 - to 2-hr white pre-pupae were collected, incubated in a $30^{\circ} \mathrm{C}$ waterbath for $12 \mathrm{hr}$, and then returned to $18^{\circ} \mathrm{C}$ for the remainder of pupal development (Hartenstein and Posakony 1990). After 4 to 5 days, pupae were dissected from their pupal cases and examined for the microchaete overproduction phenotype.

To test for $s \mathrm{o}^{71 E 1}$ suppression of ptc-Gal4/UAS-Ser-mediated ectopic outgrowth in the wing disc, sno ${ }^{71 E 1} / F M 7 C$ females were crossed to UAS-Ser males and larvae were pulsed for $12 \mathrm{hr}$ at $30^{\circ} \mathrm{C}$ during the late second and early third-instar stage. Wing discs were dissected and analyzed directly for the suppression of ectopic growth of the wing pouch in the ventral compartment.

To generate somatic mosaic clones in the adult eye, y $w$ sn $S n o^{71 E 3} f$ car, $y w S n o^{93 i}$, and $y w S n o^{E F 531}$ chromosomes were used. $w^{1118} P\left[w^{+}\right] 20 \mathrm{D}$ (from Bloomington Stock Center) males were crossed to $5 n o / F M 7 c$ females. Mitotic recombination was induced in 12- to $36-\mathrm{hr}$ embryos with X-rays at 1000 rads. Adults were screened for $w / w$ eye patches. Mosaic fly eyes were embedded in plastic and sectioned as in Rogge et al. (1991). $w^{1118}$ controls gave a patch frequency of $4 \%, y w s n s n o^{71 E 3} \mathrm{fcar}$ gave a patch frequency of $1 \%, y w s n 0^{93 i}$ gave a patch frequency of $0.6 \%$, and $y w S n O^{E F 531}$ gave a patch frequency of only $0.1 \%$. This low frequency for the $s n O^{E F 531}$ chromosome was probably the cause for our earlier inability to generate germ-line clones (Coyle-Thompson and Banerjee 1993).

\section{Acknowledgments}

We acknowledge the participation of Cathy Coyle Thompson in early aspects of RFLP mapping and deletion analysis of the sno gene. We are grateful to S. Artavanis-Tsakonas for help and advice throughout this work and we also thank E. Verheyen for two-hybrid experiments with sno constructs. We thank $M$. Wehrli for providing the genomic walk, N. Brown and G.M. Rubin for the embryo and eye disc cDNA libraries, respectively, and J. Tamkum for Drosophila genomic libraries. We thank H. Bellen, S. Benzer, S. Carroll, J. Campos-Ortega, K. Irvine, J. Jack, E. Knust, A. Martinez-Arias, K. Matthews, K. Moses, J. Posakony, V. Rodrigues, and F. Schweisguth for fly stocks and antibodies. We thank S. Rundlett and R. Mann for help with sequence alignment, Lian Liu for help in sequencing, $M$. Ganiron for mutant screens, Amanda Pickup and Gail Shirley for helpful advice and J. Lengyel, V. Hartenstein, and members of our laboratory for comments on the manuscript. This work was supported by a National Science Foundation grant /no. IBN9600391) to U.B.

The publication costs of this article were defrayed in part by payment of page charges. This article must therefore be hereby marked "advertisement" in accordance with 18 USC section 1734 solely to indicate this fact.

\section{Note added in proof}

The sequence data described in this paper have been submitted to GenBank under accession number U95760.

\section{References}

Altschul, S.F., W. Gish, W. Miller, E.W. Myers, and D.J. Lipman. 1990. Basic local alignment search tool. I. Mol. Biol. 215: 403-410.

Artavanis-Tsakonas, S. and P. Simpson. 1991. Choosing a cell fate: A view from the Notch locus. Trends Genet. 7:403408.

Artavanis-Tsakonas, S., K. Matsuno, and M.E. Fortini. 1995. Notch signaling. Science 268: 225-232.
Ashburner, M. 1989. Drosophila: A laboratory manual. Cold Spring Harbor Laboratory Press, Cold Spring Harbor, NY.

Austin, J. and J.H. Kimble. 1987. glp-1 is required in the germ line for the regulation of the decision between mitosis and meiosis in C. elegans. Cell 51: 589-599.

- 1989. Transcript analysis of $g l p-1$ and lin-12, homologous genes required for cell interactions during development of C. elegans. Cell 58: 565-571.

Bailey, A.M. and J.W. Posakony. 1995. Suppressor of Hairless directly activates transcription of Enhancer of split complex genes in response to Notch receptor activity. Genes \& Dev. 9: $2609-2622$.

Bang, A.G. and J.W. Posakony. 1992. The Drosophila gene Hairless encodes a novel basic protein that controls alternative cell fates in adult sensory organ development. Genes \& Dev. 6: 1752-1769.

Boulianne, G.L., A. de la Concha, J.A. Campos-Ortega, L.Y. Jan, and Y.N. Jan. 1991. The Drosophila neurogenic gene neuralized encodes a novel protein and is expressed in precursors of larval and adult neurons. EMBO J. 10: 2975-2983.

Busseau, I., R.J. Diederich, T. Xu, and S. Artavanis-Tsakonas. 1994. A member of the Notch group of interacting loci, deltex, encodes a cytoplasmic basic protein. Genetics 136: 585596.

Brand, A.H. and N. Perrimon. 1993. Targeted gene expression as a means of altering cell fates and generating dominant phenotypes. Development 118: 401-415.

Brown, N. and F.C. Kafatos. 1988. Functional cDNA libraries from Drosophila embryos. J. Mol. Biol. 203: 425-437.

Brou, C., F. Logeat, M. Lecourtois, J. Vandekerckhove, P. Kourilsky, F. Schweisguth, and A. Israel. 1994. Inhibition of the DNA-binding activity of Drosophila Suppressor of Hairless and of its human homolog, KBF2/RBP-Jк, by direct proteinprotein interaction with Drosophila Hairless. Genes \& Dev. 8: 2491-2503.

Cagan, R.L. and D.F. Ready. 1989. Notch is required for successive cell decisions in the developing Drosophila retina. Genes \& Dev. 3: 1099-1112.

Campos-Ortega, J.A. 1993. Early neurogenesis in Drosophila melanogaster. In The development of Drosophila melanogaster (ed. M. Bate and A. Martinez Arias), pp. 1091-1129. Cold Spring Harbor Laboratory Press, Cold Spring Harbor, NY.

Cavener, D.R. 1987. Comparison of the consensus sequence flanking translational start sites of Drosophila and vertebrates. Nucleic Acids Res. 15: 1353-1361.

Chitnis, A., D. Henrique, J. Lewis, D. Ish-Horowicz, and C. Kintner. 1995. Primary neurogenesis in Xenopus embryos regulated by a homologue of the Drosophila neurogenic gene Delta. Nature 375: 761-766.

Christensen, S., V. Kodoyianni, M. Bosenberg, L. Friedman, and J.H. Kimble. 1996. lag-1, a gene required for lin-12 and glp-1 signaling in Caenorhabditis elegans is homologous to human CBF1 and Drosophila $\mathrm{Su}(\mathrm{H})$. Development 122: 1373-1383.

Cohen, B., M.E. McGuffin, C. Pfeile, D. Segal, and S.M. Cohen. 1992. apterous, a gene required for imaginal disc development in Drosophila encodes a member of the LIM family of developmental regulatory proteins. Genes \& Dev. 6: 715729.

Corbin, V., A.M. Michelson, S.M. Abmayr, V. Neel, E. Alcamo, T. Maniatis, and Y.W. Young. 1991. A role for the Drosophila neurogeneic genes in mesoderm differentiation. Cell 67: 311-323.

Couso, J.P. and A. Martinez-Arias. 1994. Notch is required for wingless signaling in the epidermis of Drosophila. Cell 79: $259-272$. 
Couso, J.P., S.A. Bishop, and A. Martinez-Arias. 1994. The wingless signaling pathway and the patterning of the wing margin in Drosophila. Development 120: 621-636.

Couso, J.P., E. Knust, and A. Martinez-Arias. 1995. Serrate and wingless in Drosophila wing development. Curr. Biol. 5: 1437-1448.

Coyle-Thompson, C.A. and U. Banerjee. 1993. The strawberry notch gene functions with Notch in common developmental pathways. Development 119: 377-395.

de Celis, J.F., A. Garcia-Bellido, and S.J. Bray. 1996. Activation and function of Notch at the dorsal-ventral boundary of the wing imaginal disc. Development 122: 359-369.

Diaz-Benjumea, F.J. and S.M. Cohen. 1995. Serrate signals through Notch to establish a Wingless-dependent organizer at the dorsal/ventral compartment boundary of the Drosophila wing. Development 121: 4215-4225.

Diederich R.J., K. Matsuno, H. Hing, and S. Artavanis-Tsakonas. 1994. Cytosolic interaction between Deltex and Notch ankyrin repeats implicates deltex in the Notch signaling pathway. Development 120: 473-481.

Doherty, D., G. Feger, S. Younger-Shepherd, L.Y. Jan, and Y.N. Jan. 1996. Delta is a ventral to dorsal signal complementary to Serrate, another Notch ligand, in Drosophila wing formation. Genes \& Dev. 10: 421-434.

Ellisen, L.W., J. Bird, D.C. West, A.C. Soreng, T.C. Reynolds, and S.D. Smith. 1991. Tan-1, the human homolog of the Drosophila Notch gene, is broken by chromosomal translocations in T lymphoblastic neoplasms. Cell 66: 649-661.

Fehon, R.G., K. Johansen, I. Rebay, and S. Artavanis-Tsakonas. 1991. Complex cellular and subcellular regulation of Notch expression during embryonic and imaginal development of Drosophila: Implications for Notch function. J. Cell. Biol. 113: 657-669.

Fitzgerald, K., H.A. Wilkinson, and I. Greenwald. 1993. glp-1 can substitute for lin-12 in specifying cell fate decisions in Caenorhabditis elegans. Development 119: 1091-1027.

Fleming, R.J., T.N. Scottgale, R.J. Diederich, and S. ArtavanisTsakonas. 1990. The Serrate gene encodes a putative EGFlike transmembrane protein essential for proper ectodermal development of Drosophila melanogaster. Genes \& Dev. 4: 2188-2201.

Fortini, M.E. and S. Artavanis-Tsakonas. 1994. The Suppressor of Hairless protein participates in Notch receptor signaling. Cell 79: 273-282.

Greenwald, I.S., P.W. Sternberg, and H.R. Horvitz. 1983. The lin-12 locus specifies cell fate in Caenorhabditis elegans. Cell 34: 435-444.

Hartenstein, V. and J.W. Posakony. 1989. Development of adult sensilla on the wing and the notum of Drosophila melanogaster. Development 107: 389-405.

. 1990. A dual function of the Notch gene in Drosophila sensillum development. Dev. Biol. 142: 13-30.

Hartenstein, A.Y., A. Rugendorff, U. Tepass, and V. Hartenstein. 1992. The function of the neurogenic genes during epithelial development in the Drosophila embryo. Development 116: 1203-1220.

Heish, J.J. and S.D. Hayward. 1995. Masking the CBF1/RBPJ kappa transcriptional repression domain by Epstein-Barr virus EBNA-2. Science 268: 530-563.

Heitzler, P., M. Bourouis, L. Ruel, C. Carteret, and P. Simpson. 1996. Genes of the Enhancer of split and achaete-scute complexes are required for a regulatory loop between Notch and Delta during lateral signaling in Drosophila. Development 122: $161-171$

Hing, H.K., X. Sun, and S. Artavanis-Tsakonas. 1994. Modulation of wingless signaling by Notch in Drosophila. Mech.
Dev. 47: 261-268.

Huang, F., C. Dambly-Chaudiere, and A. Ghysen. 1991. The emergence of sense organs in the wing disc of Drosophila. Development 111: 1087-1095.

Irvine, K.D. and E. Wieschaus. 1994. fringe, a boundary-specific signaling molecule, mediates interactions between dorsal and ventral cells during Drosophila wing development. Cell 79: 595-606.

Jack, J. and Y. DeLotto. 1992. Effect of wing scalloping mutations on Cut expression and sense organ differentiation in the Drosophila wing margin. Genetics 131: 353-363.

Jack, J., D. Dorsett, Y. Delotto, and S. Liu. 1991. Expression of the cut locus in the Drosophila wing margin is required for cell type specification and is regulated by a distant enhancer. Development 113: 735-747.

Jan, Y.N. and L.Y. Jan. 1995. Maggot's hair and bug's eye: Role of cell interactions and intrinsic factors in cell fate specification. Neuron 14: 1-5.

Jennings, B., A. Preiss, C. Delidakis, and S. Bray. 1994. The Notch signaling pathway is required for Enhancer of split bHLH protein expression during neurogenesis in the Drosophila embryo. Development 120: 3537-3548.

Joutel, A., C. Corpechot, A. Ducros, K. Vahedi, H. Chabriat, P. Mouton, S. Alomawitch, V. Domenga, M. Cecillion, E. Marechal, J. Maciazek, C. Vayssiere, C. Cruaud, E.A. Cabanis, M.M. Ruchoux, J. Weissenbach, J.F. Bach, M.G. Bousser, and E.T. Lasserve. 1996. Notch3 mutations in CADASIL, a hereditary adult onset condition causing stroke and dementia. Nature 383: 707-710.

Kim, J., K.D. Irvine, and S.B. Carroll. 1995. Cell recognition, signal induction, and symmetrical gene activation at the dorsal-ventral boundary of the developing Drosophila wing. Cell 82: 795-802.

Kim, J., A. Sebring, J.J. Esch, M.E. Kraus, K. Vorwerk, J. Magee, and S.B. Carroll. 1996. Integration of positional signals and regulation of wing formation and identity by Drosophila vestigial gene. Nature 382: 133-138.

Kopczynski, C.C., A.K. Alton, K. Fechtel, P.J. Kooh, and M.A. Muskavitch. 1988. Delta, a Drosophila neurogenic gene, is transcriptionally complex and encodes a protein related to blood coagulation factors and epidermal growth factor of vertebrates. Genes \& Dev. 2: 1723-1735.

Kramatschek, B. and J.A. Campos-Ortega. 1994. Neuroectodermal transcription of the Drosophila neurogenic genes E(spl) and HLH-m 5 is regulated by proneural genes. Development 120: $815-826$.

Lecourtois, M. and F. Schweisguth. 1995. The neurogenic Suppressor of Hairless DNA binding protein mediates the transcriptional activation of the Enhancer of Split complex genes triggered by Notch signaling. Genes \& Dev. 9: 2598-2608.

Lefevre, G. and K. Peterson. 1972. An unusual Notch mimic: Glossy like. Drosophila Inf. Ser. 48: 126-127.

Lehmann, R., F. Jimenez, U. Dietrich, and J.A. Campos-Ortega. 1983. On the phenotype and development of mutants of early neurogenesis in Drosophila melanogaster. Wilhelm Roux's Arch. Dev. Biol. 192: 62-74.

Lindsell, C.F., C.J. Shawber, J. Boulter, and G. Weinmaster. 1995 Jagged: A mammalian ligand that activates Notch1. Cell 680: 909-917.

Matsuno, K., R.J. Diederich, M.J. Go, C.M. Blaumueller, and S. Artavanis-Tsakonas. 1995. Deltex acts as a positive regulator of Notch signaling through interactions with the Notch ankyrin repeats. Development 121: 2633-2644.

Menne, T.V. and C. Klambt. 1994. The formation of commissures in the Drosophila CNS depends on the midline cells and on the Notch gene. Development 120: 123-133. 
Myat, A., D. Henrique, D. Ish-Horowicz, and J. Lewis. 1996. A chick homologue of Serrate and its relationship with Notch and Delta homologues during central neurogenesis. Dev. Biol. 174: 233-247.

Nakao, K. and J.A. Campos-Ortega. 1996. Persistent expression of genes of the Enhancer of Split complex supresses neural development in Drosophila. Neuron 16: 275-286.

Oellers, N., M. Dehio, and E. Knust. 1994. bHLH proteins encoded by the Enhancer of split complex of Drosophila negatively interfere with transcriptional activation mediated by proneural genes. Mol. Gen. Genet. 244: 465-473.

Parr, B.A. and A.P. Mcmohan. 1995 Dorsalizing signal Wnt-7a required for the normal polarity of D-V and A-P axes in the mouse limb. Nature 374: $350-353$.

Ptashne, M. and A. Gann. 1993. Activators and targets. Nature 346: 329-331.

Phillips, R.G. and J.R. Whittle. 1993. wingless expression mediates determination of peripheral nervous system elements in late stages of Drosophila wing disc development. Development 118: 427-438.

Rabinow, L. and J.A. Birchler. 1990. Interactions of vestigial and scabrous with the Notch locus of Drosophila melanogaster. Genetics 125: 41-50.

Rhyu, M.S., L.Y. Jan, and Y.N. Jan. 1994. Asymmetric distribution of Numb protein during division of the sensory organ precursor cells confers distinct fates to daughter cells. Cell 76: 477-491.

Riddle, R.D., M. Ensini, C. Nelson, T. Tsuchida, T. Jessell, and C. Tabin. 1995. Induction of the LIM homeobox gene $\operatorname{lmx} 1$ by Wnt 7 a establishes Dorsoventral pattern in the vertebrate limb. Cell 83: 631-640.

Rogge, R.D., C.A. Karlovich, and U. Banerjee. 1991. Genetic dissection of a neurodevelopmental pathway: Son of sevenless functions downstrean of sevenless and EGF receptor tyrosine kinases. Cell 64: 39-48.

Rubin, G.M. and A. Spradling. 1982. Genetic transformation of Drosophila with transposable element vectors. Science 218: 348-353.

Rulifson, E.J. and S.S. Blair. 1995. Notch regulates Wingless expression and is not required for reception of the paracrine Wingless signal during wing margin neurogenesis in Drosophila. Development 121: 2813-2824.

Ruohola, H., K.A. Bremer, D. Baker, J.R. Swedlow, L.Y. Jan, and Y.N. Jan. 1991. Role of neurogenic genes in establishment of follicle cell fate and oocyte polarity during oogenesis in Drosophila. Cell 66: 433-449.

Schweisguth, F. and J.W. Posakony. 1992. Suppressor of Hairless, the Drosophila homolog of the mouse recombination signal-binding protein gene, controls sensory organ cell fates. Cell 69: 1199-1212.

Shawber, C., J. Boulter, J.L. Lindsell, and G. Weinmaster. 1996. Jagged2: A Serrate-like gene expressed during rat embryogenesis. Dev. Biol. 180: 370-376.

Singson, A., M.W. Leviten, A.G. Bang, X.H. Hua, and J.W. Posakony. 1994. Direct downstream targets of proneural activators in the imaginal disc include genes involved in lateral inhibitory signaling. Genes \& Dev. 8: 2058-2071.

Smoller, D., C. Friedel, A. Schmid, D. Bettler, L. Lam, and B. Yedvobnick. 1990. The Drosophila neurogenic locus mastermind encodes a nuclear protein unusually rich in amino acid homopolymers. Genes \& Dev. 4: 1688-1700.

Spana, E.P., C. Kopczynski, C.S. Goodman, and C.Q. Doe. 1995. Asymmetric localisation of Numb autonomously determines sibling neuron identity in the Drosophila CNS. Development 121: 3489-3494.

Spana, E.P. and C.Q. Doe. 1996. Numb antagonizes Notch sig- naling to specify sibling neuron cell fates. Neuron 17: 21-26.

Speicher, S.A., U. Thomas, U. Hinz, and E. Knust. 1994. The Serrate locus of Drosophila and its role in morphogenesis of the wing imaginal discs: Control of cell proliferation. Development 120: 535-544.

Spemann, H. 1938. Embryonic development and induction. Yale University Press, New Haven, CT.

Tax, F.E., J.J. Yeargers, and J.H. Thomas. 1994. Sequence of $C$. elegans lag-2 reveals a cell signaling domain shared with delta and serrate of Drosophila. Nature 368: 150-154.

Thomas, U., S.A. Speicher, and E. Knust. 1991. The Drosophila gene Serrate encodes a EGF-like transmembrane protein with a complex expression pattern in the embryos and wing discs. Development 111: 749-761.

Wehrli, M., A. DiAntonio, I.M. Fearnley, R.J. Smith, and M. Wilcox. 1993. Cloning and characterization of alpha PS1, a novel Drosophila melanogaster integrin. Mech. Dev. 43: 2136.

Wilkinson, H.A., K. Fitzgerald, and I. Greenwald. 1994. Reciprocal changes in expression of the receptor lin-12 and its ligand lag-2 prior to commitment in a C. elegans cell fate decision. Cell 79: 1187-1198.

Williams, J.A., J.B. Bell, and S.B. Carroll. 1991. Control of Drosophila wing and haltere development by the nuclear vestigial gene product. Genes \& Dev. 5: 2481-2495.

Williams, J.A., S.W. Paddock, and S.B. Carroll. 1993. Pattern formation in a secondary field: A hierarchy of regulatory genes subdivides the Drosophila wing disc into discrete subregions. Development 11: 7571-7584.

Williams, J.A., S.W. Paddock, K. Vorwerk, and S.B. Carroll. 1994. Organization of wing formation and induction of a wing-patterning gene at the dorsal/ventral compartment boundary. Nature 368: 299-305.

$\mathrm{Xu}$, T., L.A. Caron, R.G. Fehon, and S. Artavanis-Tsakonas. 1992. The involvement of the Notch locus in Drosophila oogenesis. Development 115: 913-922.

Zipursky, S.L., T.R. Venkatesh, D.B. Teplow, and S. Benzer. 1984. Neuronal development in the Drosophila retina: Monoclonal antibodies as molecular probes. Cell 36: 15 -26. 


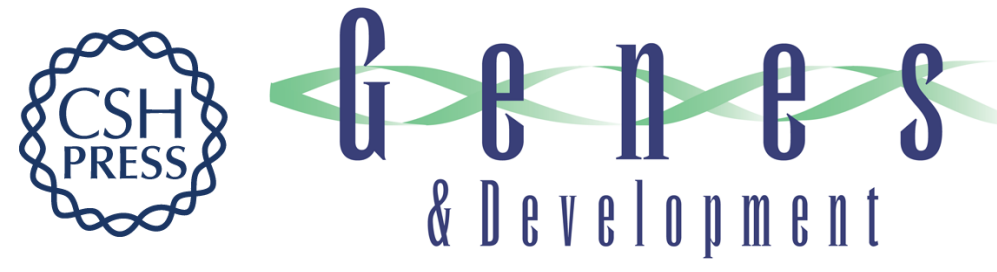

\section{strawberry notch encodes a conserved nuclear protein that functions downstream of Notch and regulates gene expression along the developing wing margin of Drosophila.}

A Majumdar, R Nagaraj and U Banerjee

Genes Dev. 1997, 11:

Access the most recent version at doi:10.1101/gad.11.10.1341

References This article cites 82 articles, 40 of which can be accessed free at:

http://genesdev.cshlp.org/content/11/10/1341.full.html\#ref-list-1

License

Email Alerting Service

Receive free email alerts when new articles cite this article - sign up in the box at the top right corner of the article or click here.

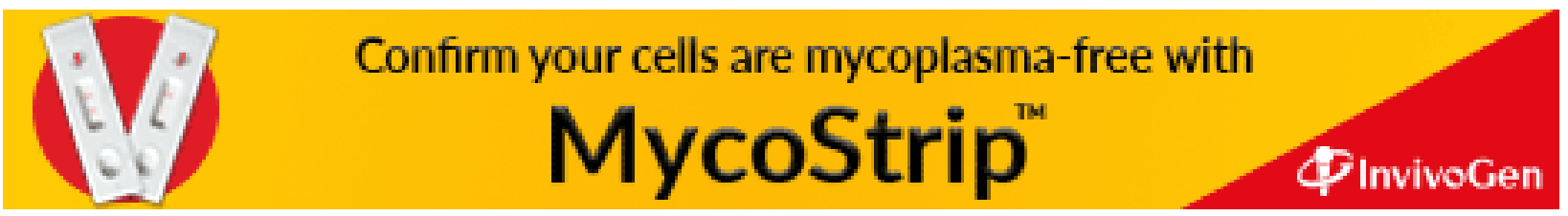

